\title{
Is transdermal menopausal hormone therapy (MHT) associated with an increased cardiovascular risk?
}

\author{
Petra Stute
}

Published online: 17 July 2014

(c) Springer-Verlag Berlin Heidelberg 2014

\section{Summary}

The US-American Women's Health Initiative Observational Study (WHI-OS) is a prospective cohort study in postmenopausal women aged 50-79 at study entry ( $n=93,676)$. Annual follow-up was performed by mailed self-administered questionnaires including questions on menopause hormone therapy (MHT). The aim of the present analysis was to compare the impact of various MHT formulations and route of delivery on incident cardiovascular diseases (CVD) [1]. Therefore, only current MHT users were included $(n=41,721 ; 45 \%$ of total cohort). MHT subgroups were defined as follows: (1) oral low-dose conjugated equine estrogens (CEE) $(<0.625$ $\mathrm{mg} /$ day), (2) oral standard-dose CEE (0.625 mg/day), (3) oral high-dose CEE ( $>0.625 \mathrm{mg} /$ day), (4) oral estrogens [CEE or estradiol (E2)], (5) oral estrogen plus progestogen therapy (EPT) (oral CEE or E2 plus progestin or progesterone), and (6) transdermal E2 therapy (ET) of any dosage plus oral progestin or progesterone in women with an intact uterus. Study endpoints were (1) major coronary heart disease (CHD) (nonfatal myocardial infarction, coronary death), (2) stroke, (3) CVD mortality, (4) total CVD (major CHD, stroke, CVD mortality), and (5) all-cause mortality. All analyses (Cox proportional hazards model) were adjusted for established CVD risk factors as well as for time since menopause ( $<10$ vs. $\geq 10$ years), and duration of MHT use ( $<5$ vs. $\geq 5$ years), respectively.

The mean duration of follow-up was 10.4 years. The majority of women used oral CEE ( $n=29,944)$, mostly as

P. Stute $(\square)$

Department of Obstetrics and Gynecology, University of Bern,

Bern, Switzerland

e-mail: petra.stute@insel.ch a standard-dose preparation (82\%) and without a combined progestogen $(55 \%)$. In contrast, use of oral E2 $(n=3,024)$ or transdermal E2 $(n=2,187)$ was much less common. However, the exact sample sizes of subgroups for different oral/transdermal E2 dosages, and for E2 with or without a progestogen, respectively, were not provided. The main findings are summarized in Table 1. Time since menopause and duration of MHT use did not have an impact on cardiovascular risks. Absolute CVD risks and all-cause mortality were lower in MHT user close to menopause (no p-level provided). The authors concluded that (1) estrogen dosage, route of delivery and type of estrogen only had a minor impact on CVD risk, however, (2) oral E2 might be associated with a lower risk of stroke, and (3) transdermal MHT and oral low-dose CEE might be associated with a lower risk of CHD compared to oral standard-dose CEE.

\section{Background}

Cardiovascular diseases are the main cause of death in women. Thus, any contributing risk factor should be avoided if possible. MHT is considered the most effective treatment for vasomotor symptom relief in postmenopausal women [2]. However, several studies have shown an increased CVD risk within the first year of MHT initiation [3-7]. The standard estrogen and progestogen used in those trials were oral CEE and medroxyprogesterone acetate (MPA), respectively. Furthermore, the majority of trials chose oral CEE at a dosage of $0.625 \mathrm{mg} /$ day considered as standard-dose CEE today. Due to the initial CVD risk increase when starting oral MHT, the question arose if type of estrogen, route of delivery and estrogen dosage may have an impact on CVD risk. An alternative estrogen type is estradiol (E2), transdermal 
Table 1 Comparison of various MHT formulations on cardioand cerebrovascular risk

\begin{tabular}{ll}
\hline Reference & Comparator \\
\hline $\begin{array}{l}\text { Oral MHT } \\
(=\text { standard-dose }\end{array}$ & $\begin{array}{c}\text { Transdermal MHT (= E2 at } \\
\text { any dosage } \pm \text { progestogen })\end{array}$ \\
\end{tabular}

Oral low-dose MHT (= lowdose CEE \pm progestogen)

$C E E$ conjugated equine estrogens, E2 estradiol, $M H T$ menopause hormone therapy, $C V D$ cardiovascular disease, $C H D$ coronary heart disease, low-dose $<0.625 \mathrm{mg}$ CEE/day, standard-dose $0.625 \mathrm{mg} \mathrm{CEE} /$ day (= oral E2 at any dosage \pm progestogen)

Oral standard-dose CEE alone E2 \pm progestogen)
Results

In favor of transdermal MHT: non-significant risk reduction for all CVD endpoints (most pronounced for major CHD: HR 0.63, $95 \%$ CI 0.37-1.06) but not for all-cause mortality

In favor of low-dose MHT: Non-significant risk reduction for major CHD, total CVD and CVD mortality but not for stroke and all-cause mortality

Oral MHT containing E2 In favor of MHT containing E2: non-significant risk reduction of stroke (HR $0.64,95 \% \mathrm{CI}$ 0.40-1.02) but no impact on other endpoints

Oral combined MHT (= CEE/ No significant difference for any endpoint patches and gels are an alternative route of delivery, and nowadays various estrogen dosages are available ranging from high-dose, standard-dose, low-dose to ultralow-dose estrogen [8]. Possibly, physiological E2 has a better pharmacodynamic and pharmacokinetic profile compared to CEE, a complex of multiple biologically active estrogens [9]. The advantage of transdermal estrogen application is avoiding the hepatic first-pass-effect causing a pro-coagulant state $[10,11]$. And finally, the effect of estrogens on CVD risk might be dose-dependent, possibly making the lowest dosage the safest one.

So far, there are two large-scale trials investigating the impact of estrogen dosage and route of delivery on risk of stroke $[12,13]$. First, in a population-based nested casecontrol study comparing 15,710 stroke survivors with 59,958 controls, transdermal estrogen therapy did not reveal an increased risk of stroke for up to an estrogen dosage of $50 \mu \mathrm{g} /$ day (adjusted RR $0.81,95 \%$ CI $0.62-1.05$ ), while oral low- and standard-dose estrogen therapy increased the risk of stroke appreciably (adjusted RR 1.28, $95 \%$ CI 1.15-1.42) even after thorough adjustment for known risk factors for stroke [12]. Second, in comparison to never MHT user, a prospective cohort study, the Nurses' Health Study, found a significantly increased risk of stroke in postmenopausal women using oral standard- (adjusted RR $1.54,95 \%$ CI 1.31-1.81) or high-dose CEE (adjusted RR $1.62,95 \%$ CI 1.23-2.14) but not in those using oral lowdose CEE (adjusted RR 0.93, $95 \%$ CI 0.62-1.40) [13]. There are only few larger studies investigating the impact of estrogen formulation on ischemic heart disease. First, in a population-based nested case-control study comparing 1,013 myocardial infarction survivors with 5,000 controls MHT was shown to reduce the risk of myocardial infarction regardless of route of delivery (oral estrogens: adjusted OR 0.66 ; $95 \%$ CI $0.50-0.88$, and transdermal E2: adjusted OR 0.75 ; $95 \%$ CI $0.47-1.21$ ) [14]. Similarly, in the second population-based nested case-control study comparing 4,537 myocardial infarction survivors with 27,220 controls current and past MHT use was associated with a decreased risk of myocardial infarction regardless of route of delivery (oral MHT: adjusted OR 0.77, $95 \%$ CI 0.66-0.90, and transdermal MHT: adjusted OR 0.66, $95 \%$ CI 0.49-0.88) [15]. The Danish Sex Hormone Register Study (DaHo RS), a prospective cohort study, found a neutral effect on risk of myocardial infarction for any current MHT use (RR 1.03, $95 \%$ CI 0.95-1.11). Subgroup analysis revealed a significantly lower risk with transdermal route of delivery compared to oral unopposed estrogen therapy $(p=0.04)$ [16].

There are two not yet published RCT in postmenopausal women addressing the impact of 5 years of treatment with different estrogen types and route of delivery on surrogate markers of cardiovascular health with carotid mediaintima-thickness (CIMT) progression as primary endpoint. The RCT Kronos Early Estrogen Prevention Study (KEEPS) compares the impact of low-dose oral or transdermal E2 with placebo in recently postmenopausal women, respectively [17]. The RCT Early versus Late Intervention Trial with Estradiol (ELITE) compares the impact of oral low-dose E2 ( \pm micronized progesterone) with placebo in either early or late postmenopausal women, respectively (ClinicalTrials.gov Identifier: NCT00114517). So far, preliminary results have been presented at international conferences on menopause revealing either a positive (ELITE; International Menopause Society, Cancun 2014), or neutral (KEEPS; North American Menopause Society, Orlando 2012) effect of E2 on CIMT progression in early postmenopausal women, respectively. In both trials, risks of coronary and cerebrovascular disease were not increased in MHT user.

\section{Comment}

This prospective cohort study, WHI-OS, is the largest study to date investigating the impact of different estrogen types, route of delivery and estrogen dosages on various single 
and combined cardiovascular endpoints. However, despite the large sample size and long duration of follow-up, the present WHI-OS analysis may not give a definite statement on whether or not transdermal and low-dose MHT display a more beneficial cardiovascular profile than oral or standard-dose MHT, respectively. First, due to the observational nature of the WHI-OS, selection bias through allocation of transdermal estrogen to women at risk for CHD and stroke cannot be excluded and would mitigate any result in favor of the transdermal route. Secondly, sample sizes of women using transdermal MHT $(n=2,187)$, and oral low-dose CEE $(n=2,149)$ were quite small. Accordingly, subgroup analysis for different E2 dosages in transdermal MHT or progestogen type in combined MHT would not have been reliably possible. Next, risk assessment for each endpoint was based on baseline MHT use. Thus, the analysis did not account for possible modifications of MHT formulation during followup. Finally, the study only included current MHT user. However, previous studies have shown an increased cardiovascular risk within the first year after MHT initiation, especially for oral estrogens. Thus, the increased incidence of cardiovascular events within the first year of MHT use may have been missed which may lead to an underestimation of the prevalence of cardiovascular events. In conclusion, the WHI-OS provides further hints for a safer cardiovascular profile of transdermal MHT. Data from RCTs like KEEPS will hopefully add more profound information.

\section{References}

1. Shufelt CL, Merz CN, Prentice RL, Pettinger MB, Rossouw JE, Aroda VR, Kaunitz AM, Lakshminarayan K, Martin LW, Phillips LS, Manson JE (2014) Hormone therapy dose, formulation, route of delivery, and risk of cardiovascular events in women: findings from the Women's Health Initiative Observational Study. Menopause 21:260-266. doi:10.1097/GME.0b013e31829a64f9

2. de Villiers TJ, Gass ML, Haines CJ, Hall JE, Lobo RA, Pierroz DD, Rees M (2013) Global Consensus Statement on menopausal hormone therapy. Maturitas 74:391-392. doi:10.1016/j.maturitas. 2013.02.001

3. Rossouw JE, Anderson GL, Prentice RL, LaCroix AZ, Kooperberg C, Stefanick ML, Jackson RD, Beresford SA, Howard BV, Johnson KC, Kotchen JM, Ockene J, Writing Group for the Women's Health Initiative I (2002) Risks and benefits of estrogen plus progestin in healthy postmenopausal women: principal results From the Women's Health Initiative randomized controlled trial. JAMA 288:321-333

4. Manson JE, Chlebowski RT, Stefanick ML, Aragaki AK, Rossouw JE, Prentice RL, Anderson G, Howard BV, Thomson CA, LaCroix AZ, Wactawski-Wende J, Jackson RD, Limacher M, Margolis KL, Wassertheil-Smoller S, Beresford SA, Cauley JA, Eaton CB, Gass M, Hsia J, Johnson KC, Kooperberg C, Kuller
LH, Lewis CE, Liu S, Martin LW, Ockene JK, O’Sullivan MJ, Powell LH, Simon MS, Van Horn L, Vitolins MZ, Wallace RB (2013) Menopausal hormone therapy and health outcomes during the intervention and extended poststopping phases of the Women's Health Initiative randomized trials. JAMA 310:1353-1368. doi:10.1001/jama.2013.278040

5. Manson JE, Hsia J, Johnson KC, Rossouw JE, Assaf AR, Lasser NL, Trevisan M, Black HR, Heckbert SR, Detrano R, Strickland OL, Wong ND, Crouse JR, Stein E, Cushman M, Women's Health Initiative I (2003) Estrogen plus progestin and the risk of coronary heart disease. N Engl J Med 349:523-534. doi:10.1056/ NEJMoa030808

6. Grodstein F, Manson JE, Colditz GA, Willett WC, Speizer FE, Stampfer MJ (2000) A prospective, observational study of postmenopausal hormone therapy and primary prevention of cardiovascular disease. Ann Intern Med 133:933-941

7. Hulley S, Grady D, Bush T, Furberg C, Herrington D, Riggs B, Vittinghoff E (1998) Randomized trial of estrogen plus progestin for secondary prevention of coronary heart disease in postmenopausal women. Heart and Estrogen/progestin Replacement Study (HERS) Research Group. JAMA 280:605-613

8. Birkhauser MH, Panay N, Archer DF, Barlow D, Burger H, Gambacciani M, Goldstein S, Pinkerton JA, Sturdee DW (2008) Updated practical recommendations for hormone replacement therapy in the peri- and postmenopause. Climacteric 11:108-123. doi:10.1080/13697130801983921

9. Bennink HJ (2008) Reprint of Are all estrogens the same? Maturitas 61:195-201

10. Zegura B, Guzic-Salobir B, Sebestjen M, Keber I (2006) The effect of various menopausal hormone therapies on markers of inflammation, coagulation, fibrinolysis, lipids, and lipoproteins in healthy postmenopausal women. Menopause 13:643-650. doi:10. 1097/01.gme.0000198485.70703.7a

11. Brosnan JF, Sheppard BL, Norris LA (2007) Haemostatic activation in post-menopausal women taking low-dose hormone therapy: less effect with transdermal administration? Thromb Haemost 97:558-565

12. Renoux C, Dell'aniello S, Garbe E, Suissa S (2010) Transdermal and oral hormone replacement therapy and the risk of stroke: a nested case-control study. BMJ 340:c2519. doi:10.1136/bmj. c2519

13. Grodstein F, Manson JE, Stampfer MJ, Rexrode K (2008) Postmenopausal hormone therapy and stroke: role of time since menopause and age at initiation of hormone therapy. Arch Intern Med 168:861-866. doi:10.1001/archinte.168.8.861

14. Varas-Lorenzo C, Garcia-Rodriguez LA, Perez-Gutthann S, Duque-Oliart A (2000) Hormone replacement therapy and incidence of acute myocardial infarction. A population-based nested casecontrol study. Circulation 101:2572-2578

15. de Vries CS, Bromley SE, Farmer RD (2006) Myocardial infarction risk and hormone replacement: differences between products. Maturitas 53:343-350. doi:10.1016/j.maturitas.2005.06. 004

16. Lokkegaard E, Andreasen AH, Jacobsen RK, Nielsen LH, Agger C, Lidegaard O (2008) Hormone therapy and risk of myocardial infarction: a national register study. Eur Heart J 29:2660-2668. doi:10.1093/eurheartj/ehn408

17. Harman SM, Brinton EA, Cedars M, Lobo R, Manson JE, Merriam GR, Miller VM, Naftolin F, Santoro N (2005) KEEPS: the Kronos Early Estrogen Prevention Study. Climacteric 8:3-12. doi:10.1080/13697130500042417 